\title{
Effects of the intraoperative application of dexmedetomidine on hemodynamics and cerebral oxygen metabolism of patients with cerebrovascular malformations
}

\author{
Feng Liang, Peng Chen, Chunlu Zhang and Fanglei Han ${ }^{a}$ \\ China-Japan Union Hospital of Jilin University
}

\begin{abstract}
Circulatory stability of patients with cerebrovascular malformations during the surgery is critical to their prognosis. Anesthesia-induced intubation, tumor separation, clamping and other operations may cause severe fluctuations in blood pressure and even result in aneurysm rupture. As a highly efficient and selective adrenergic $\alpha 2$ receptor agonists, dexmedetomidine hydrochloride is able to regulate the release of catecholamine by means of negative feedback so as to control blood pressure. This study aims to assess the effects of dexmedetomidine hydrochloride on hemodynamics and cerebral oxygen metabolism of intraoperative patients with cerebrovascular malformations.
\end{abstract}

\section{Materials and methods}

\subsection{Clinical information}

This study has been approved by the Ethics Committee of our hospital. In addition, patients and their families all signed the informed consent. 60 patients with cerebrovascular malformations under general anesthesia were selected with age of 23-67 and weight of 52-84kg. 17 of them were female and 43 were male. ASA grading were I or II. The patients were randomly divided into 2 groups with 30 each. 30min before anesthesia, they were treated with intramuscular injection of $1 \mathrm{mg}$ penehyclidine hydrochloride, After entering the room, they were injected with Lactated Ringer's solution (infusion rate was $68 \mathrm{ml} / \mathrm{kg}$.hr). In addition, they're under the routine monitor of ECG, SpO2 and HR. Radial artery puncture manometry was adopted under local anesthesia. Patients in group I received a single infusion of $1 / \mathrm{kg}$ dexmedetomidine lasting for 10 minutes. Afterwards, they were treated with continuous infusion of $0.5 / \mu \mathrm{g} \mathrm{kg}$. Hr. Group II patients were infused with the same volume of normal saline. Those with less than 50 times of heart rate were given atropine treatment. After the single infusion, patients were treated with intravenous infusion of $2 \mathrm{mg}$ midazolam, $2 \mathrm{mg} / \mathrm{kg}$ propofol, $0.5 \mu \mathrm{g} / \mathrm{kg}$ sufentanil as well as $0.1 \mathrm{mg} / \mathrm{kg}$ vecuronium induction, In addition, they were inserted with endotracheal tube to control the respiration. The PetCo2 should be maintained at $30-35 \mathrm{mmHg}$.

\subsection{Anesthesia maintenance}

Target-controlled infusion of propofol was adopted with an initial concentration of $4.0 \mu \mathrm{g} / \mathrm{ml}$. It's

a Corresponding author: 23454675@qq.com 
required to adjust the infusion concentration to maintain the bispectral index (BIS) at 40-50. Appropriate amount of sufentanil and rocuronium would be given to patients based on practical situation. Internal jugular vein puncture was used for blood collection.In addition, it's essential to record the blood pressure and heart rate at 7 different timings, namely, pre-operation (T1), immediately after intubation (T2), 3 min after intubation (T3), 5 min after intubation (T4), completion of tumor separation (T5), immediately after clamping ( T6 ) as well as $30 \mathrm{~min}$ after clamping (T7). Meanwhile, it's demanded to analyze the blood gas of radial artery and internal jugular vein and to record the arterial oxygen difference $(\mathrm{PaO} 2)$, jugular bulb oxygen difference (PjvO2), arterial oxygen saturation $(\mathrm{SaO} 2)$, jugular bulb oxygen saturation $(\mathrm{SjvO} 2)$, arterial hemoglobin concentration $(\mathrm{Hb})$ as well as hemoglobin concentration of internal jugular vein (Hjvb).

Calculation in accordance with the formula: 1. The oxygen content difference between radial artery and internal jugular vein $($ DajvO2 $)=\mathrm{CaO} 2 \mathrm{Cj}$ vO2 $=(\mathrm{Hb} \times 1.34 \times \mathrm{SaO} 2+0.031 \times \mathrm{PaO} 2)-$ $(\mathrm{Hjvb} \times 1.34 \times \mathrm{S} \mathrm{j} \mathrm{vO2}+0.31 \times \mathrm{P} \mathrm{j} \mathrm{VO} 2), 2$. Cerebral oxygen extraction rate $(\mathrm{COER}): \mathrm{COER}=$ $(\mathrm{CaO} 2 \mathrm{CjvO} 2) / \mathrm{CaO} 2 \times 100 \%$

\subsection{Statistical method}

SPSS 16.0 statistical software was used for analysis. The measurement data were expressed as mean \pm standard deviation $(\mathrm{x} \pm \mathrm{s})$. One-way ANOVA was used to compare the two groups. $\mathrm{P}<0.05$ indicated a statistically difference.

\section{Results}

The BP and HR of patients in Group II at timing of T2, T3 and T4 were significantly higher than the patients of group I $(\mathrm{P}<0.05)$ as shown in Table 1. The DajvO2 of patients in group lat the timing of T5, T6 and T73 was significantly higher than those of group II while the SjvO2 was tremendously lower $(\mathrm{P}<0.05)$ as shown in Table 2 .

Table 1. Perioperative hemodynamic changes in two groups of patients

\begin{tabular}{|c|c|c|c|c|c|c|c|c|}
\hline & & $\mathrm{T} 1$ & $\mathrm{~T} 2$ & $\mathrm{~T} 3$ & $\mathrm{~T} 4$ & T5 & T6 & $\mathrm{T} 7$ \\
\hline \multirow[t]{2}{*}{$\begin{array}{l}\text { SBP(MMH } \\
\text { g) }\end{array}$} & I group & $\begin{array}{c}145.6 \pm 13 \\
2\end{array}$ & $\begin{array}{c}131.6 \pm 16 \\
7\end{array}$ & $\begin{array}{c}145.1 \pm 27 . \\
6\end{array}$ & $\begin{array}{c}139.4 \pm 14 . \\
3\end{array}$ & $\begin{array}{c}140.8 \pm 19 \\
2\end{array}$ & $\begin{array}{c}142.6 \pm 13 \\
7\end{array}$ & $\begin{array}{c}141.4 \pm 24 \\
8\end{array}$ \\
\hline & II group & $\begin{array}{c}141.5 \pm 17 . \\
7\end{array}$ & $\begin{array}{c}156.8 \pm 22 \\
9\end{array}$ & $\begin{array}{c}157.7 \pm 19 \\
8\end{array}$ & $\begin{array}{c}149.6 \pm 21 \\
1\end{array}$ & $\begin{array}{c}139.7 \pm 22 \\
6\end{array}$ & $\begin{array}{c}145.7 \pm 19 \\
8\end{array}$ & $\begin{array}{c}140.1 \pm 20 \\
3\end{array}$ \\
\hline \multirow{2}{*}{$\begin{array}{c}\mathrm{DBP}(\mathrm{mmH} \\
\mathrm{g})\end{array}$} & I group & $90.5 \pm 13.5$ & $91.6 \pm 11.7$ & $87.6 \pm 10.1$ & $89.9 \pm 17.3$ & $91.6 \pm 12.8$ & $89.7 \pm 20.4$ & $90.7 \pm 16.4$ \\
\hline & II group & $89.5 \pm 14.3$ & $99.5 \pm 13.9$ & $8.6 \pm 14.2$ & $97.6 \pm 15.9$ & $90.2 \pm 13.8$ & $90.5 \pm 18.9$ & $89.3 \pm 17.1$ \\
\hline \multirow[t]{2}{*}{$\mathrm{HR}(\mathrm{bpm})$} & I group & $72.7 \pm 9.3$ & $67.6 \pm 11.2$ & $71.8 \pm 8.7$ & $78.4 \pm 7.9$ & $73.5 \pm 12.3$ & $78.3 \pm 9.0$ & $74.2 \pm 10.7$ \\
\hline & II group & $71.7 \pm 10.2$ & $87.9 \pm 17.6$ & $89.5 \pm 13.4$ & $86.2 \pm 11.9$ & $72.7 \pm 9.6$ & $73.6 \pm 14.2$ & $72.8 \pm 11.7$ \\
\hline
\end{tabular}

Table 2. Oxygen supply and demand of two groups of patients with cerebral aneurysms before and after clamping

\begin{tabular}{|c|c|c|c|c|}
\hline & & T5 & T6 & $\mathrm{T} 7$ \\
\hline \multirow[t]{2}{*}{$\mathrm{SjvO}_{2}(\%)$} & I group & $62.1 \pm 7.1$ & $63.2 \pm 8.0$ & $62.9 \pm 8.5$ \\
\hline & II group & $71.2 \pm 6.9$ & $69.2 \pm 7.2$ & $70.3 \pm 9.7$ \\
\hline \multirow[t]{2}{*}{ Da-jv $\mathrm{O}_{2}(\mathrm{ml} / \mathrm{L})$} & I group & $55.6 \pm 11.4$ & $55.8 \pm 13.7$ & $57.8 \pm 10.1$ \\
\hline & II group & $43.8 \pm 11.3$ & $44.5 \pm 12.1$ & $43.6 \pm 10.8$ \\
\hline \multirow[t]{2}{*}{$\operatorname{COER}(\%)$} & I group & $37.5 \pm 7.1$ & $36.9 \pm 6.2$ & $39.3 \pm 8.0$ \\
\hline & II group & $31.1 \pm 5.7$ & $31.6 \pm 5.5$ & $31.4 \pm 6.7$ \\
\hline
\end{tabular}




\section{Discussion}

As far as patients with cerebrovascular malformations were concerned, before the tumor was clamped, the dramatic changes in blood pressure might lead to rupture of the tumor and bleeding. While after the clamping, the fluctuations in blood pressure might result in cerebral vasospasm as well, thus exerting a significant negative impact on the prognosis of patients. The endotracheal intubation during anesthesia, separation of the tumor, clamping aneurysm were all highly risky. The commonly used clinical method was to deepen the anesthesia or to use antihypertensive drugs so as to control blood pressure, which, however, might cause a significant reduction in blood pressure if not used properly, ultimately leading to cerebral ischemia and hypoxia.

The brain tissues were extremely sensitive to ischemia and hypoxia, and cerebral hypoxia was considered the main reason for brain damage. It's of great significance to avoid cerebral hypoxia and brain damage in the management of anesthesia. $\mathrm{SjvO} 2$ was able to indirectly reflect the cerebral oxygen consumption and the balance between cerebral oxygen supply and demand. Moreover, it could suggest that whether the cerebral blood flow met the oxygen demand of brain tissue and provide clinical basis for the early hypoxic state ${ }^{[1]}$.

This study shows that in the timing of T2, T3, T4, the BP and HR of group I patients were not significantly different from the ones before anesthesia, while the BP and HR of group II at the same time increased significantly, which suggests a more stable hemodynamics of patients in group I during the induction of anesthesia.

The reasons may be as follows: 1 . as a highly efficient and highly selective adrenergic $\alpha 2$ receptor agonists, dexmedetomidine hydrochloride is able to regulate the release of catecholamine by means of negative feedback, thus causing dose-dependent reduction in heart rate and blood pressure as well as effective decrease in the hemodynamic response and plasma catecholamine response during the intubation $^{[2]}$.

Dexmedetomidine can act on the $\alpha 2$ receptors between posterior horn of spinal cord of presynaptic membrane and interneuron postsynaptic membrane to hyperpolarize cells and inhibit the conduction of pain signals to the brain or the descending signals to the medulla oblongata and spinal cord. Noradrenaline is able to trigger the release of substance $\mathrm{P}$ in presynaptic membrane as well as other injury-like peptide, resulting in analgesic effect ${ }^{[3]}$. Dexmedetomidine itself has a mild, moderate analgesic effect ${ }^{[4]}$ and can be used with sufentanil for synergistic analgesia, which can confirm that dexmedetomidine is able to reduce the amount of intraoperative opioids as stated in the previous report ${ }^{[4,5]}$. Opioids is used to ease the tracheal intubation response.

The $\mathrm{SjvO} 2$ values of patients in both groups were within the normal range of $60 \%-75 \%$, indicating that there's no oxygen imbalance in patients of both two groups. SjvO2 $<50 \%$ for more than $5 \mathrm{~min}$ was considered abnormal ${ }^{[6]}$. The $\mathrm{SjvO} 2$ of group I in timing of T5, T6 and T7 was significantly lower than that of group II, which showed a higher oxygen utilization rate in group I. Moreover, compared with group II, the DajvO2 of patients in group I significantly increased, indicating that preoperative and intraoperative infusion of dexmedetomidine hydrochloride not only ensured the stability of patients' hemodynamics, but also significantly improved the brain tissue's extraction and utilization of oxygen so as to protect the brain of patients with cerebrovascular malformations to a certain extent.

In summary, dexmedetomidine hydrochloride can be used to ensure the stable perioperative hemodynamics of patients with cerebrovascular malformations, improve cerebral oxygen extraction rate and cerebral oxygenation.

\section{References}

1. Brassard P, Seifert T, Secher NH. Is cerebral oxygenation negatively affected by infusion of norepinephrine in healthy subject [ J]. Br J aAnaesth, 2009,102(6):800

2. Bhanan, Coa KL,MeCLFIIAN KJ. Dexmedetomidine [J ]. Drugs. 2000,59(2):263

3. Nelson LE, Lu J, Guo T, et al. The alpha2-adrenoeeptor agonist Dexmedetomidine converges 
on endogrenous sleeppromotine path-way to exert its sedative effects. [ J ]. Anesthesiology 2003,98(2):428

4. Bhana N, Goa KL, McClellan K. Dexmedetomidine[ J ] .Drugs, 2000,59:263

5. Venn RM, Grounds RM. Comparison between Dexmedetomidine and Propofol for sedation in the intensive care unit: patient and clinician perceptions [ J ].Br J Anaesth,2001,87(5):684.

6. Oh YJ, Kim JY, ShimJK, et al. Diabets mellitus does not affect jugular bulb oxygen saturation in patients undergoing off-pump coronary artery bypass graft surgery [ J ].Circ J,2008,72(8):1259 